\title{
HUBUNGAN PANJANG-BERAT DAN POLA PERTUMBUHAN IKAN KAKATUA (Chlorurus strongycephalus) DI TAMAN NASIONAL WAKATOBI
}

\section{THE STUDY OF THE LENGTH WEIGHT RELATIONSHIPS AND GROWTH OF KAKATUA FISH (Chlorurus strongycephalus) IN WAKATOBI NATIONAL PARK}

\author{
Mercy Patanda ${ }^{1}$, Urip Rahmani ${ }^{1}$ \\ ${ }^{1}$ Program Studi Pemanfaatan Sumberdaya Perikanan, \\ Fakultas Perikanan dan Ilmu Kelautan, Universitas Satya Negara Indonesia \\ Korespondensi: patandamercy@gmail.com, uriprahmani@yahoo.com
}

\begin{abstract}
Kakatua fish is an important resource in Wakatobi Regency and the fish is caught with the fishing gear, bubu, and muroami. The research was conducted in Wakatobi National Park from December 2014 until March 2015. The objective of the study was to see the growth patterns and the size of catchable fish for cockatoo (Chlorurus strongycephalus). The research method used is survey method where sampling is done by purposive (purposive sampling) and the data used is length and weight of fish. The results showed that allometric growth pattern negative and condition factor that is equal to 1,07 which means that the availability of food is still enough while the minimum size of fish caught is 31,82 $\mathrm{cm}$. The results showed that allometric growth pattern negative and condition factor that is equal to 1,07 which means that the availability of food is still enough while the minimum size of fish caught is $31,82 \mathrm{~cm}$. This result demonstrates the need for regulation for kakatua fishing (Chlorurus strongycephalus) in Wakatobi Regency in particular that is the size of catchable fish and modification of fishing gear such as passes for Bubu.
\end{abstract}

Keyword: allometric negative, condition factor, the kakatua fish, Wakatobi

\begin{abstract}
ABSTRAK
Ikan kakatua merupakan sumber daya penting di Kabupaten Wakatobi dan ikan kakatua ditangkap dengan alat tangkap jaring, bubu, dan muroami. Penelitian ini dilakukan di Taman Nasional Wakatobi pada bulan Desember 2014 sampai Maret 2015. Tujuan penelitian adalah melihat pola pertumbuhan dan ukuran pertama kali tangkap untuk ikan kakatua (Chlorurus strongycephalus). Metode penelitian yang digunakan adalah metode survei dimana pengambilan sampel dilakukan secara purposif (purposive sampling) dan data yang digunakan adalah panjang dan berat ikan. Hasil penelitian menunjukkan bahwa pola pertumbuhan allometrik negatif dan faktor kondisi yaitu sebesar 1,07 yang berarti bahwa ketersedian makanan masih cukup sedangkan ukuran minimal ikan yang tertangkap adalah $31,82 \mathrm{~cm}$. Hasil ini memperlihatkan perlunya regulasi untuk penangkapan ikan kakatua (Chlorurus strongycephalus) di Kabupaten Wakatobi dan modifikasi alat tangkap seperti celah pelolosan untuk bubu.
\end{abstract}

Kata kunci: allometrik negatif, faktor kondisi, ikan kakatua, Wakatobi 


\section{PENDAHULUAN}

Taman Nasional Kabupaten Wakatobi merupakan salah satu kawasan konservasi perairan di Indonesia, sebagaimana Keputusan Menteri Kehutanan RI No. 393/ Kpts-VI/1996. Salah satu potensi sumber daya alam laut yang tinggi dan menjadi komoditas ekspor serta target penangkapan nelayan adalah ikan kakatua (Chlorurus strongycephalus) yang hidup di terumbu karang dan terletak di Pulau Wangi-wangi Kabupaten Wakatobi.

Penangkapan ikan karang di kawasan konservasi ini dapat mempengaruhi lingkungannya terutama terumbu karang dan menurut Sopari (2014) masih terjadi tindakan destructive fishing seperti penangkapan ikan dengan bom ikan dan sianida di wilayah ini. Selain itu penangkapan ikan kakatua (Chlorurus strongycephalus) di Kabupaten Wakatobi masih menangkap ukuran ikan yang masih kecil. Sesuai dengan COREMAP CTI II tahun 2009 melaporkan bahwa tingkat kerusakan terumbu karang di Wakatobi lebih dari $50 \%$. Noronhae (2010) melaporkan bahwa overfishing di kawasan ini yang terinci dalam growth overfishing (penangkapan sebelum mencapai ukuran ideal), ecosystem overfishing (perubahan stok ikan sebagai akibat upaya penangkapan berlebihan dan tidak digantikan oleh jenis spesies "pengganti"), dan Malthusian Overfishing (penangkapan berlebih disebabkan masuknya tenaga kerja yang tergusur dari darat (land-based-activities) yang berkompetisi dengan nelayan yang telah ada dan menggunakan cara penangkapan yang merusak).

Pengelolaan ikan karang, khususnya ikan kakatua di Pulau Wangiwangi, sangat diperlukan agar tidak menimbulkan kerusakan yang berdampak pada menurunnya populasi ikan kakatua dan produktivitas nelayan. Penelitian ini mencoba memberikan data yang diperlukan dalam pola pengelolaan berdasarkan data harvest strategy dimana data panjang dan berat rata-rata badan ikan menjadi salah satu parameter utama bagi rekomendasi pengelolaan. Berdasarkan hal tersebut maka dilakukan penelitian pada sumber daya ikan karang khususnya ikan kakatua (Chlorurus strongycephalus). Penelitian ini bertujuan untuk melihat pola pertumbuhan ikan kakatua (Chlorurus strongycephalus) di perairan Kabupaten Wakatobi serta Untuk mengetahui ukuran layak tangkap untuk ikan kakatua (Chlorurus strongycephalus).

\section{METODE PENELITIAN}

Penelitian dilakukan di Pulau Wangiwangi Kabupaten Wakatobi (Gambar 1) dari bulan Desember 2014 sampai bulan Maret tahun 2015 karena Pulau Wangi-wangi Kabupaten Wakatobi merupakan pusat pemerintahan dan memiliki sumber daya ikan kakatua (Chlorurus strongycephalus).

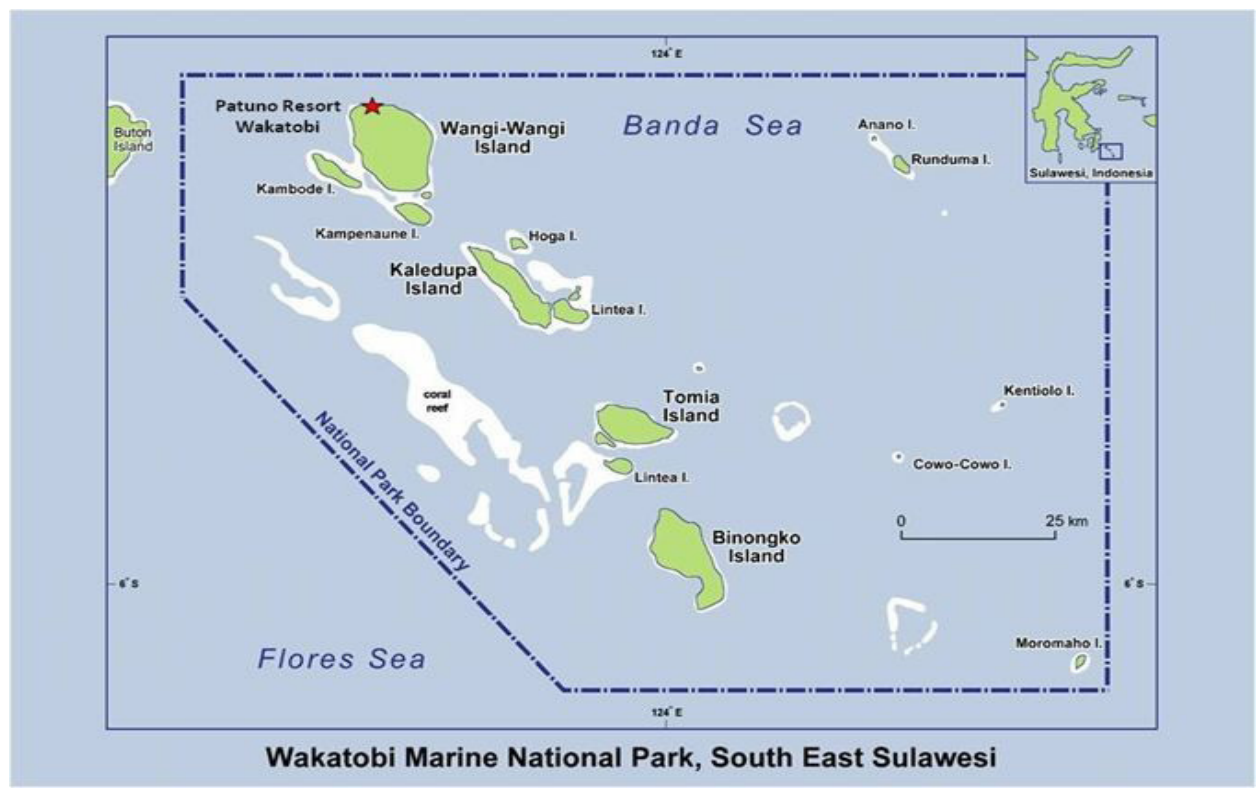

Gambar 1. Lokasi Penelitian 
Teknik pengambilan sampel dilakukan secara purposif (purposive sampling). Purposive sampling merupakan teknik sampling yang satuan samplingnya dipilih berdasarkan pertimbangan tertentu dengan tujuan untuk memperoleh satuan sampling yang memiliki karakteristik atau kriteria yang dikehendaki dalam pengambilan sampel.

Data yang dikumpulkan terdiri dari data primer dan data sekunder. Data primer terdiri dari data panjang dan berat ikan. Panjang ikan $(\mathrm{cm})$ yang diukur adalah panjang total, yaitu panjang ikan yang diukur mulai dari ujung terdepan dari kepala sampai ujung terakhir bagian ekornya. Pengambilan sampel secara purposif ini dilakukan secara acak dan jumlah sampel ikan adalah 200. Data tersebut berasal dari hasil tangkapan nelayan di perairan Kabupaten Wakatobi sedangkan data sekunder berasal dari publikasi ilmiah.

Penelitian dilaksanakan selama 4 bulan dengan beberapa tahapan yaitu:

1. Survei lapangan

2. Pengukuran panjang dan berat ikan

3. Menganalisis data primer dan data yang dianalisis adalah panjang dan ikan untuk melihat hubungan panjang dan berat ikan kakatua serta ukuran ikan yang pertama kali tertangkap (Lc)

Data dianalisis dengan melihat hubungan panjang berat ikan sehingga kita dapat mengetahui pola pertumbuhan ikan, serta berat ikan dapat dianggap sebagai fungsi dari panjangnya (Effendie 1997):

$$
W=a L^{b}
$$

Keterangan :

$$
\begin{array}{ll}
W & =\text { Berat ikan }(\mathrm{g}), \\
L & =\text { Panjang total ikan }(\mathrm{cm}), \\
a \text { dan } b & =\text { Parameter }
\end{array}
$$

$$
\log W=\log a+b \log L
$$

Nilai $b$ ditentukan dari plotting logaritma berat terhadap logaritma panjang dari sejumlah besar ikan dari berbagai ukuran, maka slope yang dihasilkan merupakan nilai $b$ yang diestimasikan (koefisien regresi). Apabila $b=3$ maka dinamakan dengan isometrik yang menunjukkan ikan tidak berubah bentuknya dan pertambahan panjang ikan seimbang dengan pertambahan beratnya. Apabila $b<3$ dinamakan allometrik negatif, bila pertumbuhan panjangnya lebih cepat dibandingkan pertumbuhan beratnya, jika $b>3$ dinamakan allometrik positif yang menunjukkan bahwa pertumbuhan beratnya lebih cepat dibandingkan dengan pertambahan panjangnya (Effendie 1997).

Faktor kondisi merupakan keadaan yang menyatakan kondisi atau kemontokan ikan dalam angka. Nilai ini dipengaruhi oleh umur, jenis kelamin, makanan dan tingkat kematangan gonad (Lagler 1956), sedangkan menurut Effendie (1997) faktor kondisi ikan didasarkan pada jenis kelamin, ukuran ikan dan waktu. Faktor kondisi ikan kakatua dihitung dengan menggunakan rumus;

$$
K_{n}=\frac{W}{a L^{b}}
$$

dimana:

$$
\begin{array}{ll}
K_{n} & =\text { Faktor kondisi } \\
W & =\text { Berat tubuh }(\mathrm{g}) \\
L & =\text { Panjang Total }(\mathrm{mm}) \\
a \text { dan } b & =\text { Konstanta }
\end{array}
$$

\section{Mengukur ukuran ikan pertama kali ditangkap (LC)}

Pendugaan ukuran pertama kali ikan tertangkap dilakukan dengan membuat grafik hubungan antara panjang ikan (sumbu X) dengan jumlah ikan (sumbu Y) sehingga diperoleh kurva berbentuk sigmoid. Nilai legth at first capture yaitu panjang pada $50 \%$ pertama kali tertangkap dihitung dengan persamaan sebagai berikut (Jones 1976 dalam Sparre \& Venema 1999) :

$$
\begin{gathered}
S_{L}^{e s t}=\frac{1}{1+\exp \left(S_{1}-S_{2} * L\right)} \\
\operatorname{Ln}\left(\frac{1}{S_{L}}-1\right)=S_{1}-S_{2} * L \\
L_{50 \%}=\frac{S_{1}}{S_{2}}
\end{gathered}
$$

dimana:

$S_{L}=$ Kurva logistik ; $S_{1}=a ; S_{2}=b S_{1}$ dan

$S_{2}=$ Konstanta pada rumus kurva logistik

\section{Faktor kondisi}

Faktor mempergunakan persamaan (Effendie, 1997):

$$
K=\frac{10^{5} W}{L^{3}}
$$

dimana:

$$
\begin{aligned}
K & =\text { Faktor kondisi } \\
W & =\text { Berat rata-rata ikan (gram) } \\
L & =\text { Panjang rata-rata ikan }
\end{aligned}
$$




\section{HASIL DAN PEMBAHASAN}

Ikan kakatua

(Chlorurus strongycephalus) (Gambar 2) merupakan ikan yang banyak ditemukan di perairan Taman Nasional Wakatobi. Ikan kakatua tergolong herbivora bentuk tubuh lonjong dan agak pipih yang memiliki lonjong. Makanan utamanya adalah algae yang menempel pada karang mati. Ikan yang memiliki corak sisik beragam ini secara berkelompok. Ikan berukuran kecil (juvenile) banyak ditemukan hidup di daerah padang lamun, sedangkan ikan berukuran dewasa hidup di daerah padang lamun, sedangkan ikan berukuran dewasa hidup di daerah terumbu karang pada kedalaman bervariasi (WWF, 2015).

\section{Hubungan panjang dan berat}

Analisis hubungan panjang dan berat menggunakan panjang total dan berat. Hubungan panjang dan berat ikan kakatua disajikan pada Gambar 3.

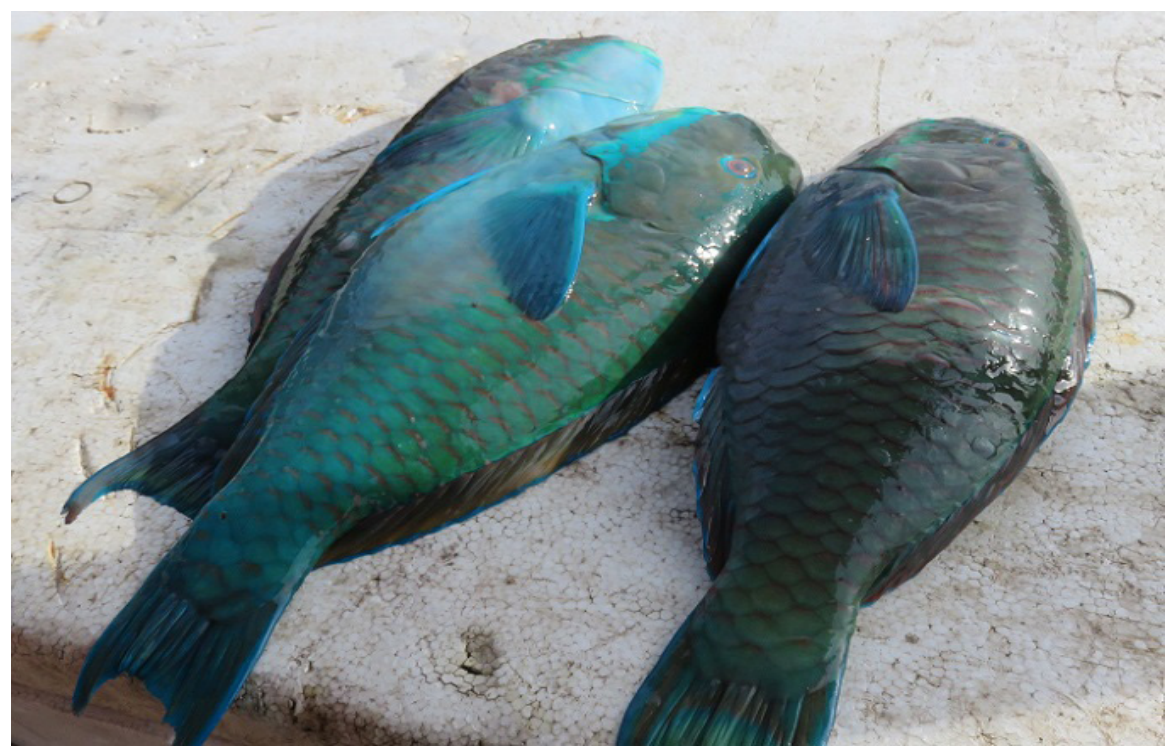

Gambar 2. Ikan kakatua (Chlorurus strongycephalus)

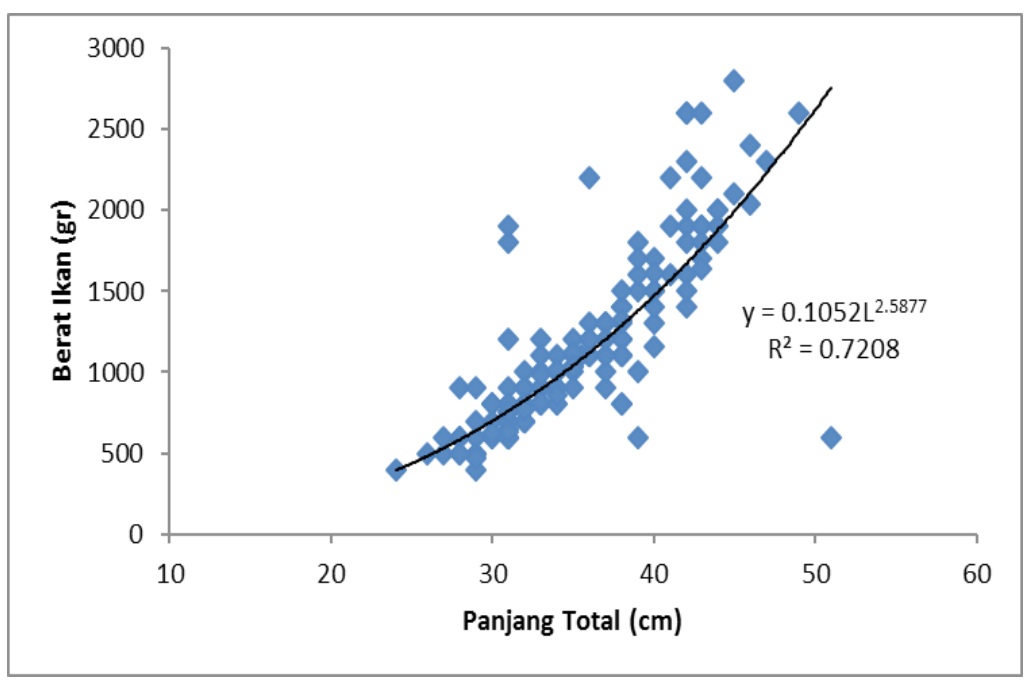

Gambar 3. Hubungan panjang berat ikan kakatua (Chlorurus strongycephalus) 
Hasil analisis hubungan panjang dan berat diketahui bahwa nilai a sebesar $-2,5877$ dan nilai q sebesar 0,1052 . Nilai $b$ yang diperoleh dan setelah dilakukan uji-t $(a=0,05)$ terhadap nilai tersebut diketahui bahwa pola pertumbuhan bersifat allometrik negatif yang berarti pertambahan panjangnya lebih cepat dari pada pertambahan berat maka tolak $H_{0}$ yaitu $b \neq 3$. Hal tersebut sesuai dengan yang dikatakan oleh Nugroho et al. (2013) bahwa pola pertumbuhan allometrik negatif, artinya pertambahan panjangnya lebih cepat dari pada pertambahan berat.

Pertambahan panjang lebih cepat dari pada pertambahan berat yang berarti ikan kakatua pada saat penelitian dalam keadaan yang cukup tersedia bahan makanan dan lingkungan yang sesuai di perairan. Makanan yang cukup tersedia dapat disebabkan oleh jumlah ikan kakatua yang banyak di perairan Kabupaten Wakatobi. Jumlah yang banyak berdasarkan hasil wawancara dengan nelayan Kabupaten Wakatobi yang menyatakan bahwa ikan kakatua mudah ditemukan dan dapat ditemukan di semua perairan Kabupaten Wakatobi. Menurut Mamangkey (2002), makanan merupakan salah safu faktor yang cukup penting dalam menentukan pertumbuhan dan kemampuan berkembang biak suatu organisme. Begitu pula yang ditemukan oleh Effendie (1997), ada beberapa faktor yang mempengaruhi pertumbuhan, diantaranya adalah faktor dalam dan faktor luar yang mencakup jumlah dan ukuran makanan yang tersedia, jumlah makanan yang menggunakan sumber makanan yang tersedia, suhu, oksigen terlarut, faktor kualitas air, umur, dan ukuran ikan serta matang gonad.

Berdasarkan analisis lambung dari ikan kakatua dari hasil tangkapan di Kabupaten Wakatobi adalah banyak ditemukan tumbuhan makrofita, gobidae dan pomacentridae. Menurut Adrim (2008) bahwa makanan ikan kakatua mengikuti pola makan tanpa pilih (non-selektif) dengan melakukan "grazing" terhadap algae halus yang tumbuh menutupi permukaan karang mati.

Berdasarkan hasil penelitian bahwa faktor kondisi sebesar 1,07 yang berarti faktor kondisi menunjukkan bahwa ikan kakatua memiliki sumber makanan yang cukup. Faktor kondisi adalah suatu angka yang menunjukkan kegemukan ikan. Dari sudut pandang nutrisional, faktor kondisi merupakan akumulasi lemak dan perkembangan gonad (Le Cren 1951). Sesuai dengan penelitian dari Yulius et al. (2015) yang menyatakan bahwa kondisi terumbu karang di perairan Pulau Wangiwangi termasuk dalam kategori sedang hingga baik. Hal tersebut berarti kesediaan makanan dari ikan kakatua tersedia karena ikan kakatua makanannya adalah lumutlumut yang menempel di Karang. Selain itu menurut Nurdawati (2010) faktor kondisi ikan dapat tergantung dari jumlah organisme, kondisi organisme, lingkungan, suhu.

\section{Ukuran pertama kali tangkap}

Alat tangkap untuk ikan kakatua di Kabupaten Wakatobiadalahjaring, muroami, dan bubu. Tabel 1 menunjukkan bahwa ukuran panjang ikan kakatua (Chlorurus strongycephalus) yang tertangkap dengan panjang antara $24 \mathrm{~cm}$ sampai $45 \mathrm{~cm}$ dengan panjang rata-rata ikan yang tertangkap adalah 35,09 cm sesuai dengan Gambar 4.

Pengaturan ukuran panjang ikan sangat diperlukan karena dengan pengaturan ukuran panjang ikan akan memberi kesempatan kepada ikan berkembang biak sehingga keberlanjutan ikan kakatua tetap tersedia. Penentuan ukuran minimal yang ditangkap sangat diperlukan seperti yang dikatakan oleh Ault et al. (2006) bahwa dengan penentuan ukuran minimum penangkapan akan memberikan kesempatan hewan untuk dewasa, mencapai biomassa dan setidaknya memastikan pengganti reproduksi dari pasangan pemijahan serta penurunan tingkat kematian ikan dengan demikian terwujudnya keberlanjutan populasi ikan.

Penangkapan ikan kakatua (Chlorurus strongycephalus) dilakukan secara tradisonal tetapi berdasarkan hasil wawancara dengan nelayan bahwa masih ditemukan nelayan menggunakan alat tangkap yang tidak ramah lingkungan seperti bom dan sianida. Hal tersebut sesuai dengan Clifton (2013) yang mengatakan bahwa kasus yang paling banyak ditemukan adalah menangkap ikan dengan bom dan banyak hasil tangkapan ikan karang yang ditemukan di pasar internasional ditangkap dengan sianida.

Berdasarkan hasil penelitian, direkomendasikan untuk pembuatan ukuran ikan minimal yang tertangkap khususnya untuk ikan kakatua. Selain itu, peratuan tentang pengaturan akan alat tangkap karena jumlah alat tangkap yang 
banyak akan menyebabkan tekanan kepada sumber daya ikan. Rekomendasi lainnya adalah modifikasi dari alat tangkap bubu sehingga ikan yang tertangkap adalah ikan yang memiliki ukuran besar. Bubu yang ada di Kabupaten Wakatobi masih belum memiliki celah pelolosan sehingga perlu penambahan celah pelolosan, sehingga ukuran ikan yang kecil dapat keluar dari bubu yang ada. Modifikasi alat tangkap bubu ikan dapat sesuai dengan saran WWF (2015) yaitu bubu yang memiliki celah pelolosan. Celah pelolosan untuk bubu yang disarankan oleh WWF (2015) memiliki ukuran antara $15 \mathrm{~cm}$ sampai $20 \mathrm{~cm}$ dan celah pelolosan ini bertujuan agar ikan yang berukuran kecil dapat keluar.

Tabel 1. Ukuran panjang ikan kakatua yang tertangkap

\begin{tabular}{|c|c|c|c|c|c|c|c|}
\hline $\begin{array}{c}\text { Length } \\
\text { group }\end{array}$ & Midlength & Jumlah & $\%$-ase & Kumulatif & & & SL est \\
\hline $19-21$ & 20 & 2 & 0,143 & 0,143 & 6 & 1,792 & 0,062 \\
\hline $21-23$ & 22 & & 0 & 0,143 & 6 & 1,792 & 0,095 \\
\hline $23-25$ & 24 & & 0 & 0,143 & 6 & 1,792 & 0,142 \\
\hline $25-27$ & 26 & & 0 & 0,143 & 6 & 1,792 & 0,208 \\
\hline $27-29$ & 28 & & 0 & 0,143 & 6 & 1,792 & 0,293 \\
\hline $29-31$ & 30 & 1 & 0,071 & 0,214 & 3,667 & 1,299 & 0,396 \\
\hline $31-33$ & 32 & 3 & 0,214 & 0,429 & 1,333 & 0,288 & 0,510 \\
\hline $33-35$ & 34 & 4 & 0,286 & 0,714 & 0,4 & $-0,916$ & 0,622 \\
\hline $35-37$ & 36 & & 0 & 0,714 & 0,4 & $-0,916$ & 0,723 \\
\hline $37-39$ & 38 & 1 & 0,071 & 0,786 & 0,273 & $-1,299$ & 0,805 \\
\hline $39-41$ & 40 & 2 & 0,143 & 0,929 & 0,077 & $-2,565$ & 0,867 \\
\hline $41-43$ & 42 & & 0 & 0,929 & 0,077 & $-2,565$ & 0,912 \\
\hline $43-45$ & 44 & 1 & 0,071 & 1 & 0 & & \\
\hline \multicolumn{2}{|c|}{ Total } & 14 & 1 & & & & \\
\hline
\end{tabular}

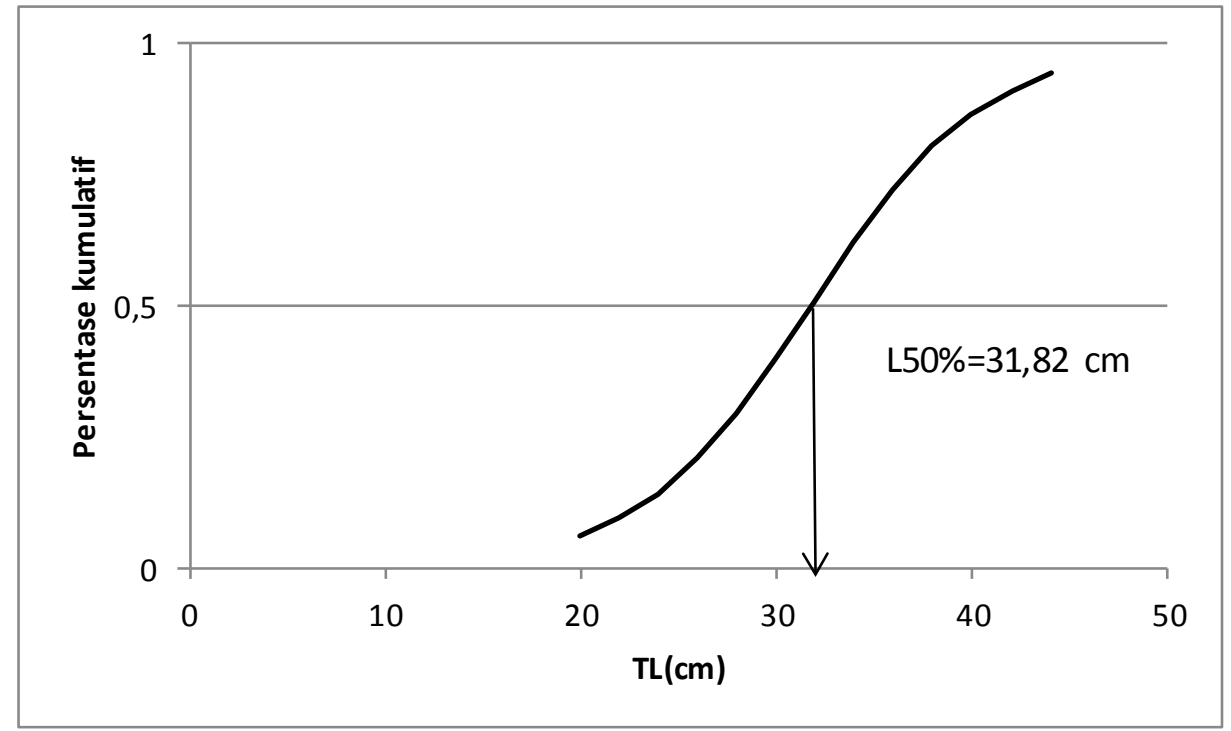

Gambar 4. Ukuran ikan kakatua yang layak tangkap 


\section{KESIMPULAN DAN SARAN}

\section{Kesimpulan}

Pola pertumbuhan dari ikan kakatua adalah pola pertumbuhan panjang-berat ikan bersifat allometrik negatif pertambahan panjang lebih dominan dari pertambahan beratnya sedangkan faktor kondisi dari ikan kakatua sebesar 1,07 yang berarti bahwa ikan kakatua memiliki sumber makanan yang cukup. Ukuran layak tangkap untuk ikan kakatua (Chlorurus strongycephalus) adalah $31,82 \mathrm{~cm}$.

\section{Saran}

Beberapa saran yang bisa dikemukakan berkaitan dengan hasil penelitian ini antara lain:

1. Perlu dilakukan peneltian untuk musim barat dan musim timur sehingga dapat dikeluarkan penetapan ukuran ikan untuk musim barat dan musim timur.

2. Perlu dilakukaan pendataan panjang ikan dan berat kakatua (Chlorurus strongycephalus) yang kontinue sehingga dapat diketahui sumber daya ikan kakatua (Chlorurus strongycephalus).

3. Perlu dilakukan penelitian untuk ikan karang lainnya yang merupakan komoditas ekspor.

\section{DAFTAR PUSTAKA}

Ault JS, Smith SG, Bohnsack JA, Harper DE, McChellan DB. 2006. Building sustainable fisheries in Florida coral reef ecosystem : positive signs in the Dry Tortugas. Bulletin of Marine Science. 78(3) : 633-654.

Adrim M. 2008. Aspek Biologi Ikan Kakatua (Suku Scaridae). Jurnal Oseana. XXXIII (1) : 41-50

Clifton J. 2013. Refocusing Conservation Through a Cultural Lens: Improving governance in the Wakatobi National Park, Indonesia. Marine Policy. 41 :
80-86

Lagler. 1956. Freh Water Fishery Biology. W.M.C. Brown Company Publisher. Dubuque. Iowa.

Le Cren ED. 1951. Length-Weight Relationship and Seasonal Cycle in Gonad Weight and Condition in The Perch (Perca fluviatilis). Journal of Animal Ecology. 20(2) : 201-219.

Mamangkey JJ. 2002. Hubungan Perkembangan Otolit Dengan Pertumbuhan Ikan Terbang (Cypselurus poeciloptefns) di Perairan Teluk Manado. Jurnal lktiologi 1rtdonesia. 2 (1) : 15-19.

Nugroho, Estu. 2013. Nila Unggul 1- Cet.1. Penebar Swadaya. Jakar

Nurdawati S. 2010. Pola Pertumbuhan dan Faktor Kondisi Ikan Tilan (Mastacembelus erythrotaenia Bleeker 1850) sehubungan dengan Perubahan Musim dan Tipe Habitat di Sungai Musi Bagian Hilir. Seminar Nasional Biologi Fakultas Biologi UGM, Yogyakarta.

Effendie MI. 1997. Metode biologi perikanan. Yayasan Dewi Sri. Bogor. 112 hlm.

Noronhae MD. 2010. Strategi Segitiga Karang (Coral Triangle). Pride Rare.

Sopari H, Ngakan PO, Darmawan S. 2014. Model kolaborasi perencanaan antara Balai Taman Nasional Wakatobi dan Pemerintah Kabupaten WAKATOBI dalam pengelolaan sumber daya alam hayati secara lestari. Joernal Sains \& Teknologi. 14(2) : 189-198.

Sparre P and Venema SC. 1999. Introduction to Tropical Fish Stock Assesment. Part 1.Manual 1. FAO Fisheries Technical Paper (Revised edition).

Yulius, Novianti N, Arifin T, Hadiwijaya SL, Rahmada, Purbani D. 2015. Distribusi Spasial Terumbu Karang Di Perairan Pulau Wangi-Wangi Wakatobi. Jurnal Ilmu dan Teknologi Kelautan Tropis. 7(1) : 59-69.

WWF. 2015. Seri Panduan Perikanan Skala Kecil Ikan Kakatua dan Baronang. WWF-Indonesia. 